\title{
Evaluation of the Response of Buried Steel Pipelines Subjected to the Strike-slip Fault Displacement
}

\author{
Mohsen Oghabi ${ }^{\mathrm{a}}$, Mehdi khoshvatan ${ }^{\mathrm{b}}$, Aminaton Marto ${ }^{\mathrm{c}}$ \\ ${ }^{a}$ Department of Civil Engineering, College of Engineering, Kermanshah Branch, Islamic Azad University, Kermanshah, Iran. \\ ${ }^{b}$ Young Researches and Elite Club, Kermanshah Branch, Islamic Azad University, Kermanshah, Iran. \\ ${ }^{c}$ Faculty of Civil Engineering, University Technology Malaysia, 81310 UTM Johor Bahru, Johor, Malaysia.
}

Received 02 May 2017; Accepted 06 September 2017

\begin{abstract}
In this paper, the response of buried steel pipeline subjected to the strike-slip fault displacement is studied. This study aimed to identify the seismic fault under the pipe at the intersection of large displacement (up to 3 meter fault displacement) and identify failure modes in the pipe. Innovation studies the effect of thickness ratio of the diameter of the pipe failure modes of the fault displacement. The nonlinear finite element method analysis was conducted. By using ABAQUS software, nonlinear finite element analysis was carried out on the pipeline under fault displacement. Numerical modelling aimed at obtaining the amount of displacement corresponding to the nonlinear behaviour in the pipeline, as well as identifying failure modes pipes in displacement from 0.2 to 3 meter in diameter to thickness ratio, taking into account the impact of the pipeline. The results showed the nonlinear behaviour of the displacement $57.5 \mathrm{~cm}$ pipeline damage starts and the displacement of 1 meter buckling occurs in pipes. The displacement of 1 meter fault, failure mode is local buckling pipe, and displacement and deformation of the pipe is 1 meter looks like the letter S. The displacement of 1.5 meter high ( 3 meter) failure mode tube is wrinkling. And deformation of the pipe in the fault displacement of 1.5 meter, like the letter Z. With the increase in displacement from 1.5 meter to high wrinkling occurs in pipes and up to 3 meter displacement continues. Plastic strain in the fault displacement of $80 \mathrm{~cm}$ in diameter to thickness ratio of 112 and 96 occurs, Plastic strain ratio of diameter to thickness of 86 does not occur. Reduction in the diameter of the thickness has a positive impact on reducing plastic strain in the pipe.
\end{abstract}

Keywords: Buried Pipelines; Strike Slip Fault; Buckling; Fault Displacement

\section{Introduction}

The most important possible damage to buried pipelines is the permanent ground displacement and seismic wave. The causes of permanent ground displacement are:

- Lateral spreading of soil liquefaction

- Landslides

- Fault displacement.

Displacement of the soil around the pipe leads to the creation of the interaction between soil and pipe, and the interaction between the soil and the pipe damages the pipes. Due to large permanent ground displacement caused in the pipeline is nonlinear behavior.

* Corresponding author: mehdikhoshvatan@gmail.com

DOI: http://dx.doi.org/10.21859/cej-03093

> This is an open access article under the CC-BY license (https://creativecommons.org/licenses/by/4.0/).

(C) Authors retain all copyrights. 
In 1906 and 1971, San Francisco earthquakes of moment magnitude 7.8 and 6.6 caused much damage to tanks and buried pipelines. In one case, soil at the confluence of pipes and fault displacement was 2.5 meter [1]. In the 1994 Northridge earthquake of moment magnitude 6.7, 1000 failures and damages were observed in pipelines [2]. In the ChiChi earthquake of moment magnitude 7.7 in 1999, nearly $8000 \mathrm{~km}$ of water distribution pipelines were damaged, 200 failures occurred in the gas pipeline, while fault displacement was reported up to 4meter [3]. The 1999 Kobe earthquake of moment magnitude 6.9 struck vast destruction in pipelines; gas leaks from urban gas pipeline led to fires, and damage to water pipes cut off water to one million people. Fault displacement at the confluence of the pipeline was 2.1 meter [4]. In 2002, the Alaska earthquake was along about $350 \mathrm{~km}-$ long fault and fault displacement was in eight places in the pipelines [5].

With an overview of past earthquakes, it can be concluded that the peak ground displacement of buried steel pipelines subjected to the strike-slip fault displacement has been an important factor in pipeline failure.

Newmark and Hall (1975) the analytical model to calculate the tensile strain at the confluence of pipes provided with fault; connection to the soil pipe is assumed and the interaction between pipe and soil slip is ignored [6]. Kennedy et al (1977) assuming constant pipeline radius of curvature of the curve changes the shape obtained. The effect of friction forces in the near-fault ground and pipes considered the main limitation of this model, not considering the flexural stiffness of the pipelines [7]. Shinzoko and Koike (1979) assuming no slip and friction between pipe and soil. Based on the model Newmark and Hall (1975) conversion factor to calculate the strain obtained in the model Newmark [8]. Wang and Yeh (1985) design criteria discussed buried pipelines, pipes' response for different displacement, angle fault crossings, burial depth, and diameter achieved. Wang and Yeh's model limits the curvature of the pipe as fixed [9]. Chiu et al (1994) assuming varied pipe curvature obtained displacement functions, differential equations that can be solved by numerical methods [10]. Takada et al (1998) suggested a new method to calculate the pipe wall strain. Modeling the pipe close to the fault with shell elements and further with beam elements was done. For maximum strain on the pipe wall and bending angle, some equations were obtained [11]. O'Rourke and Liu (1999) presented a new method for calculating the maximum axial strain of pipes. Given the impact of slip between pipe and soil in increasing failure at fault, he considered a model, taking into account the occurrence of slip along the entire length and pipe in modeling [1]. Data (1999) expressed some methods for modeling soil and pipes with simplifying assumptions [12].

American lifeline guideline (2001) presented methods for the analysis of pipelines buried under faulting. It points to the complexity of the behavior of soil and pipe due to the nonlinear behavior of materials and the impact of the pipe interaction. Pipe modeling was proposed with two elements of beam and shell and linearly springs the soil. It was expressed that the most accurate method of modeling is the soil with the solid element and as the mass of soil with regard to the elastoplastic behavior [13]. Takada and Hassani (2001), with the finite element method and a combination of beam and shell for modeling the pipe, presented an equation for maximum strain at the bending of the pipe. The main difference between his works with former researchers is to consider large deformations in the pipe [14]. Karamitros et al (2006), with the beam on elastic foundation theory, obtained equations for calculating strain and nonlinear stress. In his model inspired by the model of Wang and Ye (1985) and based on the Kennedy et al (1977) model and through the finite element method, he divided the pipe into sections and obtained some relationships [15]. Abaddon et al (2008) conducted experiments with centrifuges for buried polyethylene pipelines in the sand ground and under strike-slip fault. The results showed that burial depth and diameter of the pipe are effective in pipe's response and soil moisture has no significant impact on strain made in pipes [16]. Vazouras et al in (2010) conducted numerical modeling. The angle of fault and the pipeline was assumed vertically. The effect of soil type on the pipe's response was measured. They concluded that with the displacement of 0.67 meter in sticky clay, buckling occurs in pipes [17]. Vazouras et al (2012) investigated the effect of the angle of pipe crossings in fault for different angles. They concluded that on the negative angle of pipe crossings in fault, local buckling is the main cause of failure and internal pressure has a positive impact on pipe deformation [18]. Rofooei et al (2015) conducted some tests on buried steel pipelines subjected to reverse fault motion. For sandy soil and steel pipes, displacement of $60 \mathrm{~cm}$ was applied on the pipes as much as possible. It was found that when the pipe is subjected to faulting many large plastic hinges come up in the pipe. Three parameters of created axial strain, pipe deformation, and pipes distortion in the pipe were examined [19]. E.Uckan et al (2015) investigated two variables of displacement and a length of pipe being affected by the fault. They concluded that the critical strain in displacement occurs about two Place of the diameter of the pipe. The critical displacement means a displacement that is formed in the plastic hinges in pipe [20].

In this paper, the response of buried steel pipes under the strike-slip fault was obtained with respect to appropriate performance measures such as local buckling, taking into account the interaction between soil and pipes for various amounts of displacement obtained. For this purpose, the ratio of diameter to thickness is selected from 45 to 112.

\section{Materials and Methods}

The analysis of the seismic response of buried pipelines subjected to crossing the strike-slip faults is a complicated issue and requires three-dimensional modeling of soil pipe and also analysis of big deformations. Because of cost and 
restrictions on access to laboratory facilities, precise and acceptable results can be obtained through numerical modeling. The flowchart pertinent to the modeling and analysis process are shown in Figure 1.

Research has shown that the shell element and finite element methods of pipe damage can be modeled with great precision. A failure in the continuous pipelines often occurs in the range of nonlinear materials of the pipe. Near the fault, there is a big deformation. As a result, geometric nonlinearity and nonlinearity of the materials, both should be considered in modeling. The Mohr-Coulomb behavioral model used in soil behavior modeling is used. Soil material properties are presented in Table 1.

The Ramberg-Osgood behavioral model was the best model to show the plastic behavior of steel pipelines. Equation 1 shows the stress and strain behavior for the pipe. In Figure 2, Ramberg-Osgood's chart can be seen. In Equation 1, $\varepsilon$ is strain and $\sigma$ is stress.

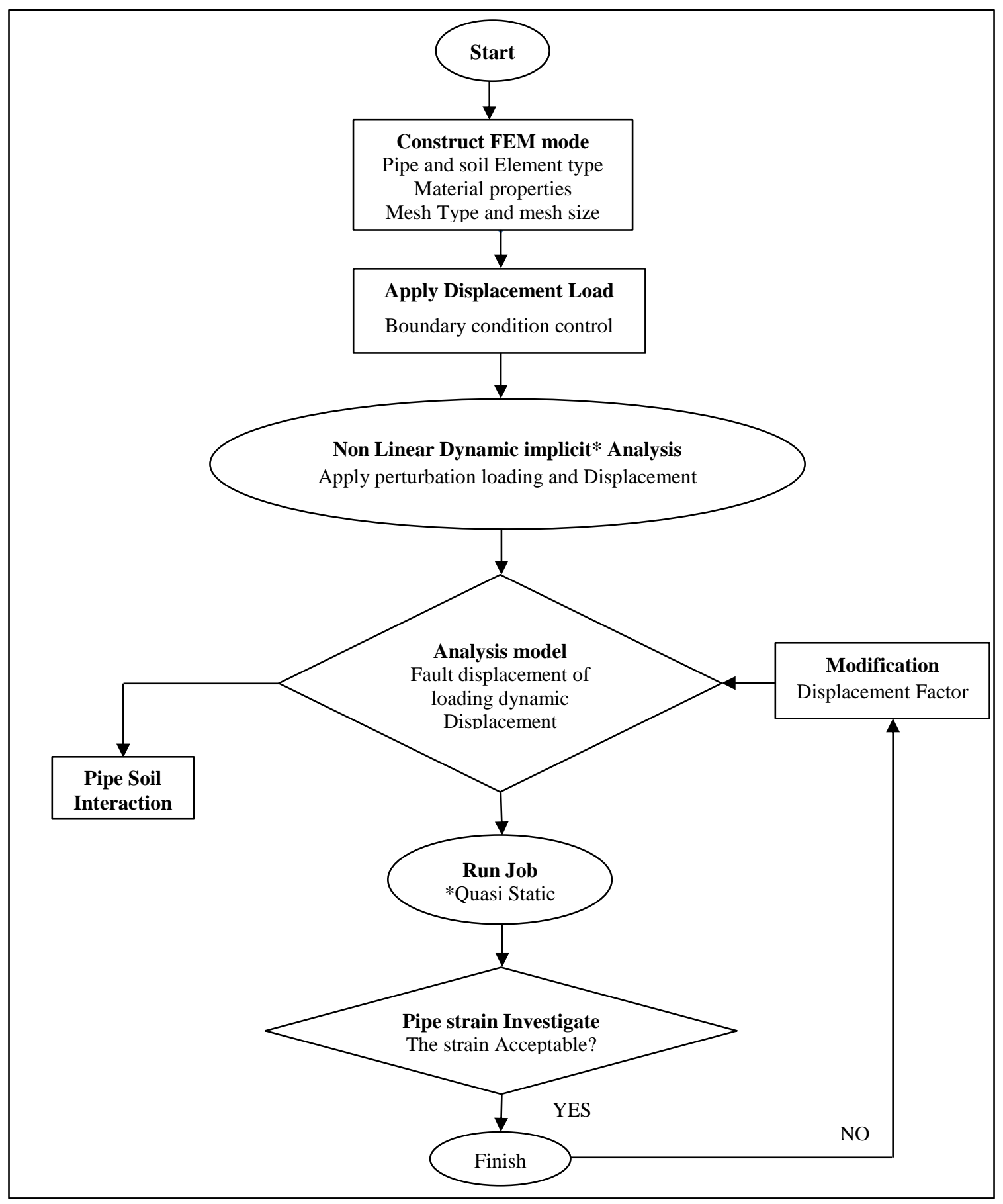

Figure 1. Flowchart of finite element analysis [21, 22] 


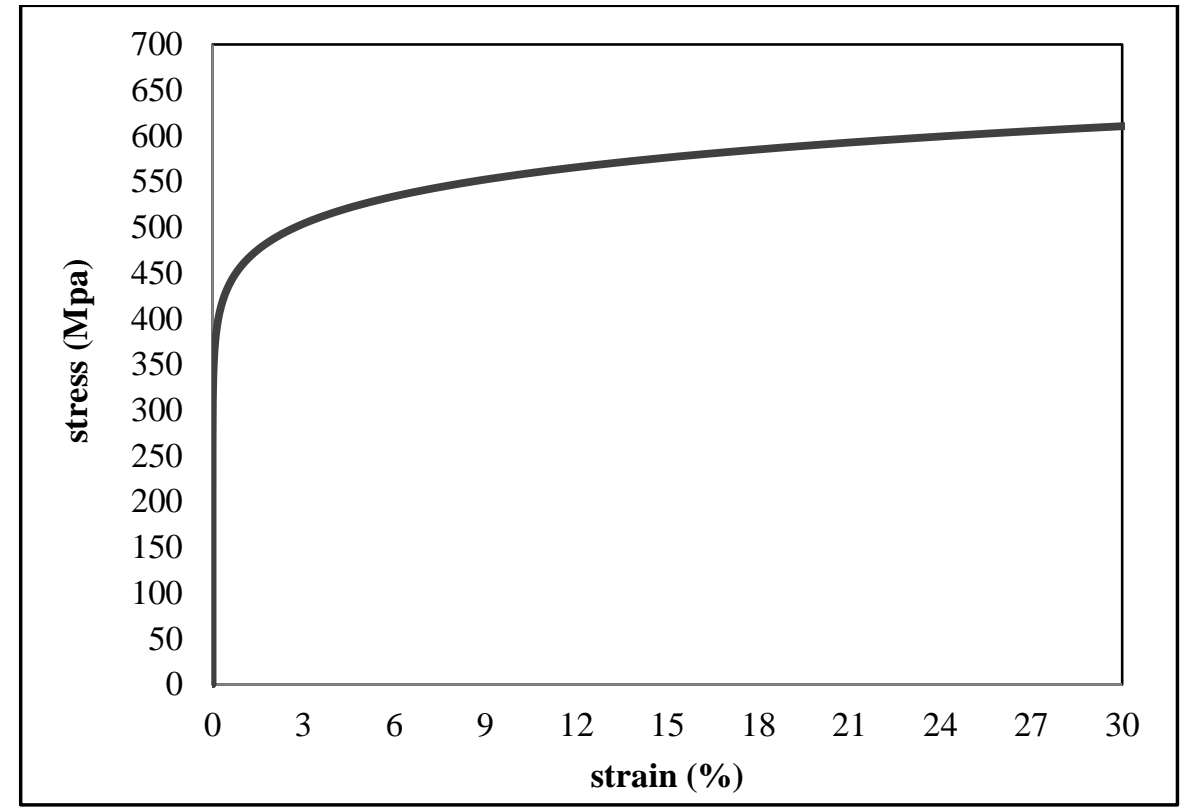

Figure 2. Ramberg Osgood steel pipes Chart

$\varepsilon=\frac{\sigma}{210 * 10^{9}}\left[1+\frac{10}{1+12}\left(\frac{\sigma}{450 * 10^{6}}\right)^{12}\right]$

Where:

$\varepsilon-$ Strain, $\sigma-$ stress (N.m)

Table 1. Soil properties used in modeling

\begin{tabular}{ccc}
\hline Soil parameters & Value & Unit \\
\hline Features of soil materials & Cohesive sand & \\
Density & 1850 & $\mathrm{Kg} / \mathrm{m}^{3}$ \\
Poisson's ratio & 0.3 & \\
Modulus of Elasticity & $20 \times 10^{6}$ & Mpa \\
friction Angle & 33.5 & degree \\
Features of soil materials & 5 & \\
\hline
\end{tabular}

Dimensions of soil length, width, and depth of 60 in 10 in 5 meters and diameter of $914 \mathrm{~mm}$ are used. Because of the quasi-static nature of the fault displacement, the quasi-static type of analysis is selected. For the pipe and soil interaction, the type of contact surface is used, the interaction between the pipelines outer wall and inner layers, two blocks of soil are applied. The amount of friction is selected between the soil and 0.3. Displacement is applied through the boundary conditions. Degrees of freedom are in a fixed way and one side of the pipe is bounded, and displacement is applied through nodes in moving the block of soil. For the soil type C3D8R, a cube element of eight of node linear and for continuous pipe element of S4R, we consider a four-node. Displacement of 0.2 to 0.3 meters was conducted in the soil and pipes in controlled way and effect of displacement was compared by examining the numerical values.

\section{Numerical Approach}

\subsection{Geometry with Dimensions}

To save the calculation time and memory, the dimension of the models was usually assumed as 60 meter of the pipeline and soil length, pipe diameter, and soil dimension, according to the many research by reference [17, 18,20 , 21]. Pipe and soil and fault model are shown the Figure 3. 

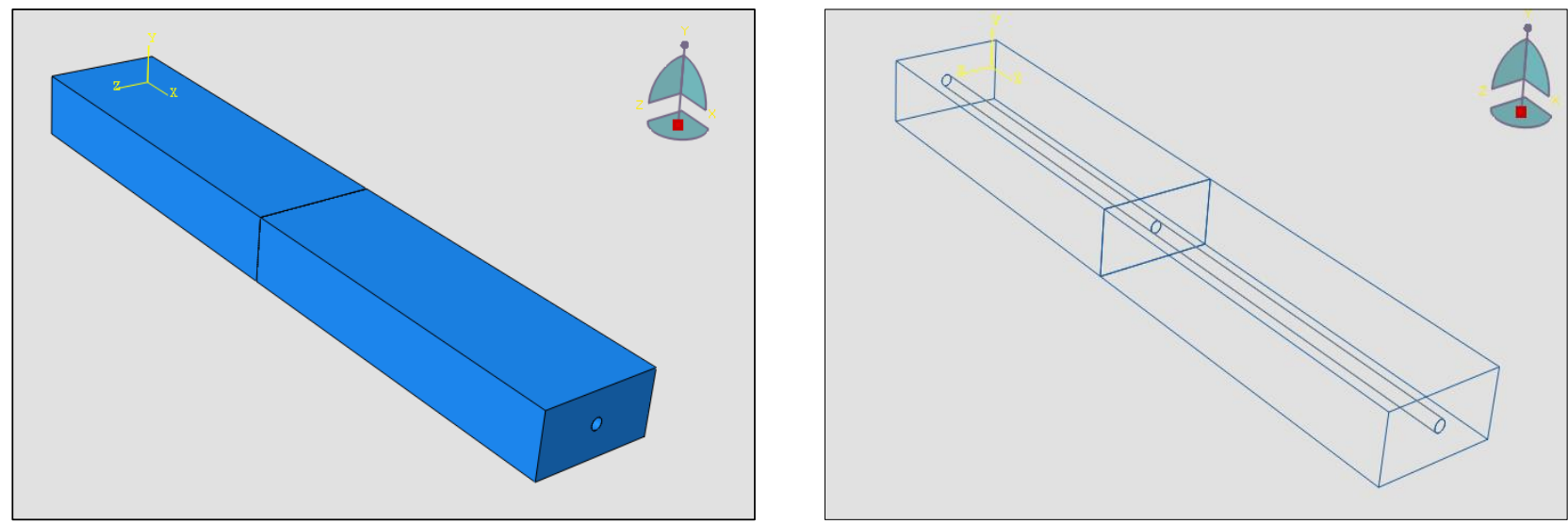

Figure 3. The modeling of buried steel pipeline subjected to fault displacement

\subsection{Meshing}

The finite element mesh for the soil formation and steel pipe is depicted in Figure 4, four-node reduced-integration shell elements (S4R) are employed for modeling the steel pipe, whereas eight-node reduced-integration (brick shape) elements (C3D8R) are used to simulate the surrounding soil.

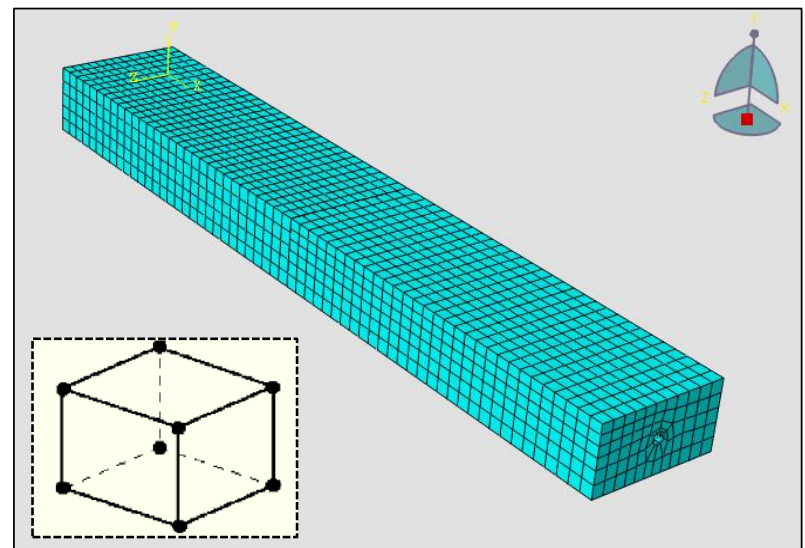

a) C3D8R solid mesh for soil

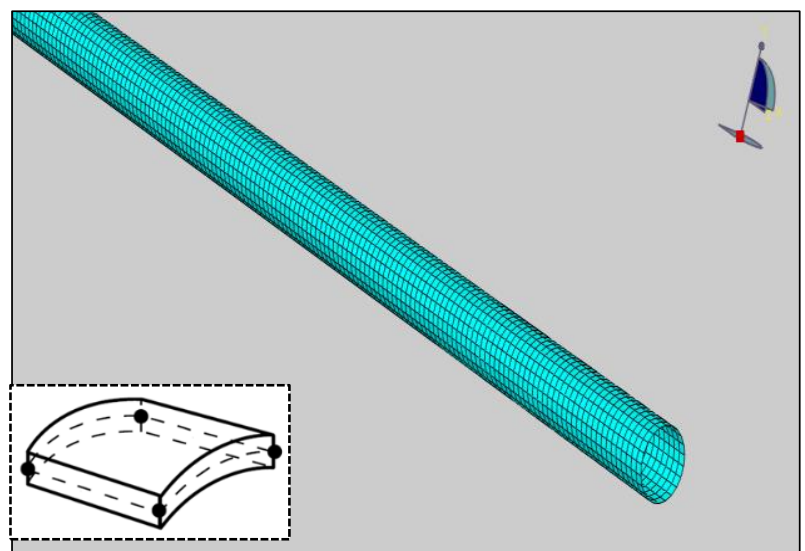

b) S4R shell mesh for pipe

Figure 4. finite element mesh of soil and pipeline

\subsection{Boundary and Initial Condition}

The vertical boundary nodes of the first soil block remain fixed in the horizontal $\mathrm{x}$-direction (including the end nodes of the pipe and soil), whereas a fault displacement $(0.2-3$ meter) in the external nodes of the other (moving) block in the horizontal $\mathrm{z}$ direction (including the end nodes of the pipe and soil). Figure 5, shows the simplified model for pipesoil and fault displacement. Figure 6, shows the finite element (soil and pipe condition and fault displacement) in this research.

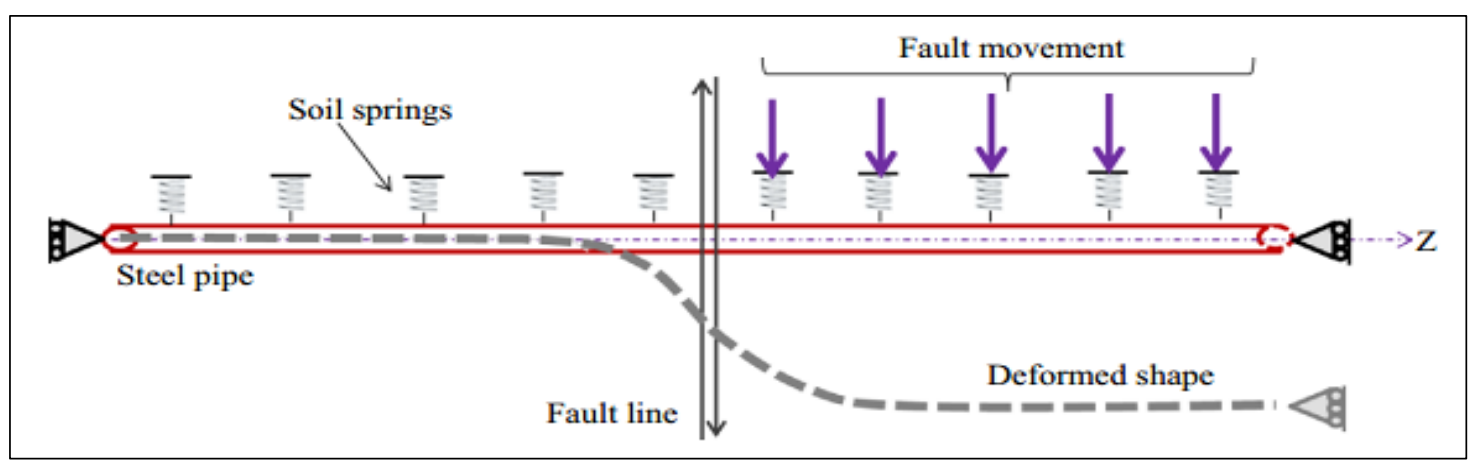

Figure 5. Simplify model for pipe-soil and fault displacement [23] 


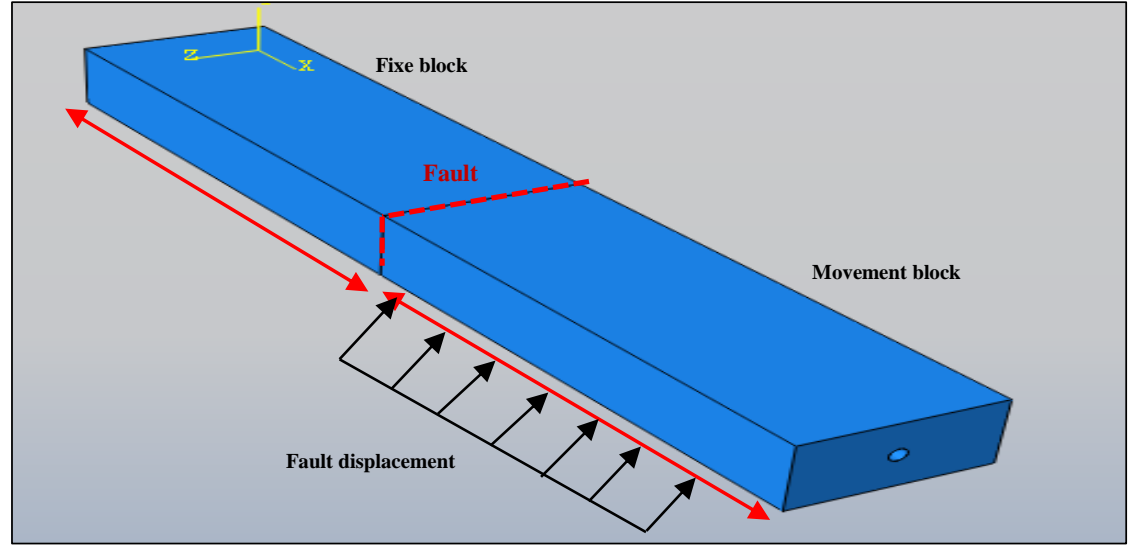

Figure 6. Finite element model of the soil-pipe-fault system

\subsection{Software Governing Equations}

The quasi-static formulations are governed by the equation of static equilibrium, which in the absence of forces of the body takes the following form Equation 2:

$\sigma_{i j, j}=0$

Where $\sigma_{i j}$, $\mathrm{j}$ means the partial derivatives of the Cauchy tensor with respect to the Cartesian coordinates $\mathrm{x}_{\mathrm{j}}$. This equation expresses the equilibrium in the current configuration, i.e. in the mesh after the deformation. This formulation allows domain integration to replace the more tedious solution of the original differential equations. The integral over the domain volume $\mathrm{V}$ is:

$\int_{v} \sigma_{i j, j} \delta u_{i} d V=0$

The equation mentioned above together with the appropriate constitutive equation allows to define quasi-static finite element formulations by means of the following set of matrices of nonlinear equations:

$K^{t} u^{t}=F^{t}$

The quasi-static finite element formulations used in the analysis of metal forming and resistance welding processes are commonly implemented together with implicit solution schemes. The main advantage of implicit schemes on alternative solutions based on explicit procedures is that the equilibrium is checked at each increment of time by iterative procedures to minimize the residual force vector $\mathrm{R}(\mathrm{u})$, which is calculated as follows in the iteration number $\mathrm{n}$ :

$R_{n}^{t}=K_{n-1}^{t} u_{n}^{t}-F^{t}$

The nonlinear sets of equations. 4, derived from quasi-static implicit formulations, can be solved by different numerical techniques, such as direct iteration (also known as "successive substitution") and Newton-Raphson methods. In the direct iteration method, the stiffness matrix is evaluated for the displacements of the previous iteration in order to reduce Equation 5. to a linear set of equations. The Newton-Raphson standard method is an alternative iterative method based on a linear expansion of the residual $\mathrm{R}(\mathrm{u})$ near the velocity estimate in the previous iteration:

$\mathrm{u}_{\mathrm{n}}^{\mathrm{t}}=\mathrm{u}_{\mathrm{n}-1}^{\mathrm{t}}+\Delta \mathrm{u}_{\mathrm{n}}^{\mathrm{t}}$

The main advantage of the quasi-static implicit finite element formulations is that the equilibrium conditions are checked at each increment of time in order to minimize the residual force vector $\mathrm{R}(\mathrm{u})$ within a specified tolerance.

\section{The Numerical Result}

Through the conducted simulation, the result for different values of fault displacement of 0.2 to 3 meter and thickness of 8.5 to 20 millimeter and diameter to thickness ratio of 45 to 112 are articulated. The moment that first plastic strain is created in the pipe, the starting point is nonlinear behavior in the pipe. In the following it will be pointed out that local buckling in less than 1-meter displacement and pipe wrinkling in displacement over 1-meter are modes of failure in the pipe.

\subsection{The Effect of Different Values of Fault Displacement on the Pipeline Response}

The pipe displacement for the diameter ratio of 112 is shown in Figure 7. As the figure specifies, buckling occurs in two points of the pipe. These two points are close to the fault line of buckling. By increasing the faulting, buckling increases and failure occurs in the pipe. To increase the pipe's thickness has the useful effect of the buckling mode of pipe buckling subjected to the strike-slip fault. By increasing the fault displacement, the pipe displacement increases in 
the pipeline as bending and displacement in pipes of more thickness was like S and less thickness was like Z. Pipe displacement will be smooth, on the other hand, and the pipeline buckling in fewer displacements will not be serious and important. But in bigger displacement in 1.2 meter, two bends occur in the upper part of the $\mathrm{Z}$ shaped pipeline. The pointed points show the buckling point.

\subsection{The Effect of Diameter Ratio to Pipeline Thickness}

When the diameter ratio to thickness reduces, two points of buckling incidence is likely. When the diameter ratio to thickness is less, the maximum Von Mises stress occurs around two points of likely buckling. But when the diameter ratio to thickness is more, Von Mises stress increases in two points being near the faulting, and the distance of two points from each other in the maximum of tension and minimum amount of diameter ratio to thickness increases. The pipeline in the diameter ratio to the thickness more than 86 big deformations and nonlinear is shown. Mostly the most important place of the pipeline is near the faulting and strain more than other parts around faulting.

\subsection{The Effect of Fault Displacement}

The buckling points of pipeline in the sea, pipeline wrinkling deformation are visible on the left and right side. Through increasing the faulting displacement, the range and level of wrinkling increases. But the number of wrinkling decreases and bigger strains occur in two main regions of wrinkling. The created axial strain in the pipe for displacement of 0.2 and 0.4 meter does not lead to big deformation and nonlinear behavior in materials. In conducted analysis for displacement of 0.575 meter and diameter ratio to the thickness of 112 and pipe thickness of $8.5 \mathrm{~mm}$, the pipe goes into a nonlinear phase.

In diameter ratios by the thickness of 96 and 112, plastic strain occurs in the pipe. The amount of displacement in which peak ground displacement occurs in the pipe and it enters the nonlinear behavior quickly and there is buckling in the pipe, displacement equals 1 meter. The maximum axial strain about 0.075 occurs in the pipe by the thickness of 8.5 $\mathrm{mm}$. The maximum of created strain in the displacement of 1.2 meter is around 0.027 and is 112 in the diameter ratio to thickness. By increasing the displacement more than 1.5 meter, wrinkling takes place in the pipe and wrinkling is the mode in which failure happens. In Table 2, pressure strains and Table 3, tensile strains are being created in the pipe subjected to the fault displacement. To focus and concentrate the strain leads to the occurrence of wrinkling in a part of the pipe in which pressure strain is created. Due to too much displacement in which fault imposes on the pipe, wrinkling continues to the point that leads to pipe failure.
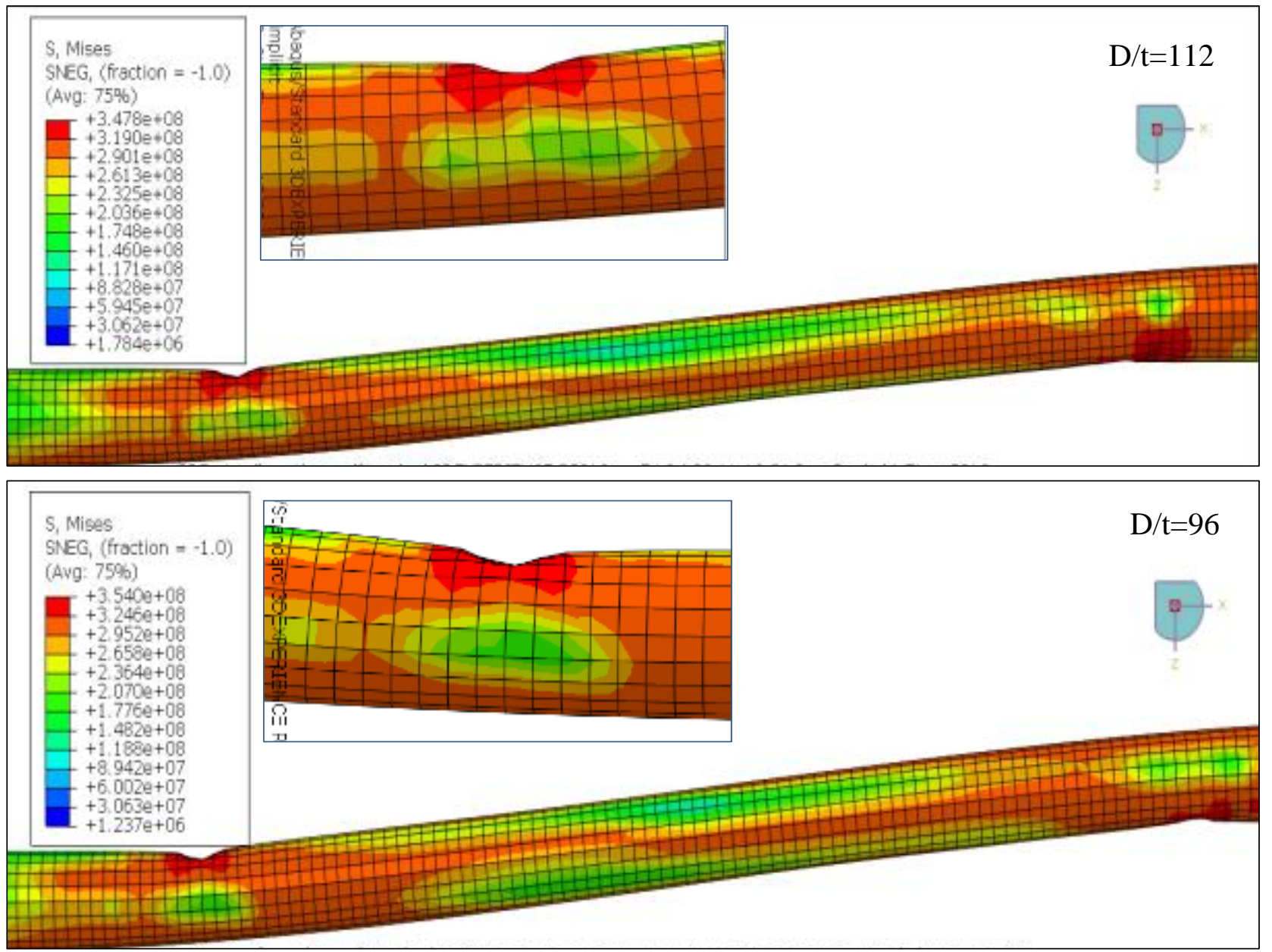

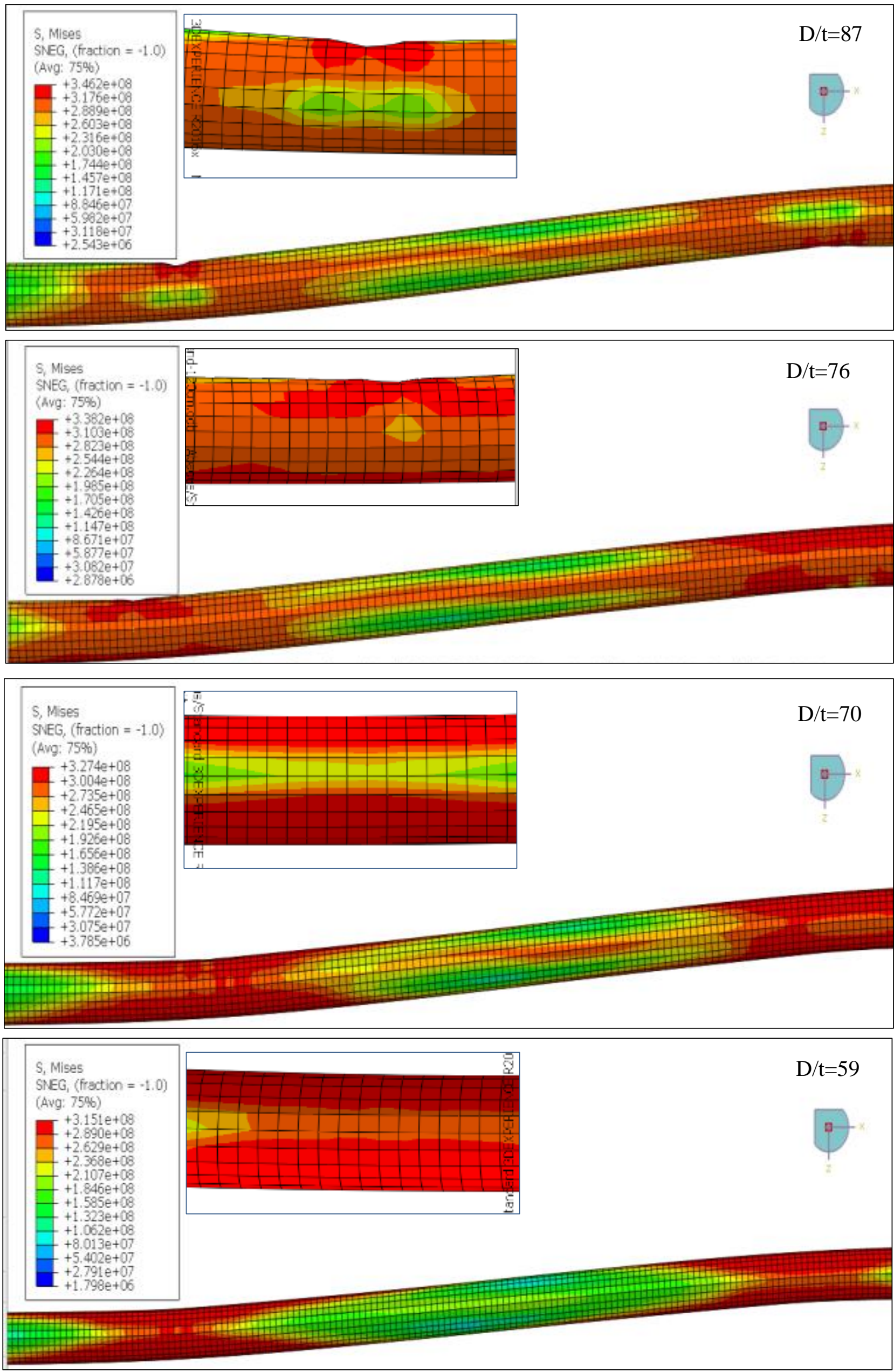

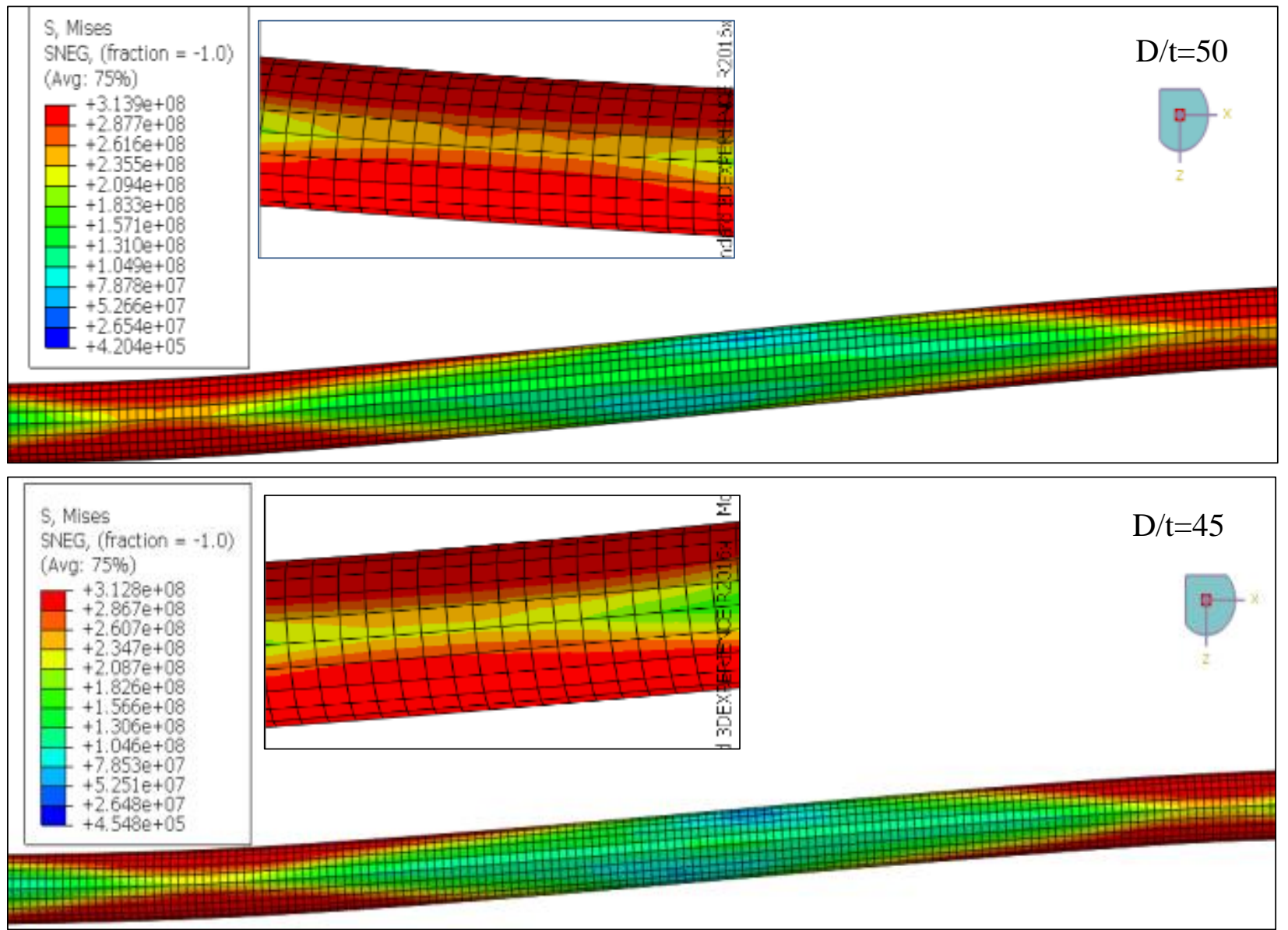

Figure 7. The effect of diameter ratio to the thickness of pipe displace in 1.2 displacement. The diameter ratio to thickness is 45 to 112 (von mises stress)

Table 2. Pipe pressure strain in 0.2 to 3 meter fault displacement and diameter ratios by the thickness of 45 to 112

\begin{tabular}{ccccccccc}
\hline $\begin{array}{c}\text { Fault Displacement } \\
(\mathbf{m})\end{array}$ & \multicolumn{9}{c}{ Diameter To thickness Ratio } \\
\hline 0.2 & 0.0005 & 0.00052 & 0.00055 & 0.00058 & 0.00053 & 0.00067 & 0.00068 & 0.0007 \\
0.4 & 0.0007 & 0.00076 & 0.00083 & 0.00089 & 0.00095 & 0.001 & 0.0011 & 0.0012 \\
0.6 & 0.0008 & 0.0019 & 0.0021 & 0.003 & 0.00412 & 0.00513 & 0.0052 & 0.006 \\
0.8 & 0.00098 & 0.0046 & 0.0052 & 0.0066 & 0.0076 & 0.0089 & 0.0098 & 0.0106 \\
1 & 0.00508 & 0.00642 & 0.00911 & 0.01308 & 0.01645 & 0.024 & 0.0256 & 0.032 \\
1.2 & 0.01291 & 0.0204 & 0.0224 & 0.0254 & 0.037 & 0.044 & 0.0481 & 0.0527 \\
1.5 & 0.01622 & 0.0248 & 0.034 & 0.0385 & 0.0413 & 0.0461 & 0.0509 & 0.0745 \\
2 & 0.0179 & 0.0261 & 0.0386 & 0.0418 & 0.0491 & 0.0577 & 0.0624 & 0.0812 \\
2.5 & 0.02018 & 0.0304 & 0.0427 & 0.0442 & 0.0605 & 0.0651 & 0.0771 & 0.0916 \\
\hline
\end{tabular}

Table 3. Pipe tensile strain in 0.2 to 3 meter fault displacement and diameter ratios by the thickness of 45 to 112

\begin{tabular}{|c|c|c|c|c|c|c|c|c|}
\hline $\begin{array}{l}\text { Fault Displacement } \\
(\mathrm{m})\end{array}$ & \multicolumn{8}{|c|}{ Diameter To thickness Ratio } \\
\hline 0.2 & 0.0005 & 0.00052 & 0.00055 & 0.00058 & 0.00053 & 0.00067 & 0.00068 & 0.0007 \\
\hline 0.4 & 0.0007 & 0.00076 & 0.00083 & 0.00089 & 0.00095 & 0.001 & 0.0011 & 0.0012 \\
\hline 0.6 & 0.0008 & 0.0019 & 0.0021 & 0.003 & 0.00412 & 0.00513 & 0.0052 & 0.006 \\
\hline 1.2 & 0.01291 & 0.0204 & 0.0224 & 0.0254 & 0.037 & 0.044 & 0.0481 & 0.0527 \\
\hline 1.5 & 0.01622 & 0.0248 & 0.034 & 0.0385 & 0.0413 & 0.0461 & 0.0509 & 0.0745 \\
\hline 2 & 0.0179 & 0.0261 & 0.0386 & 0.0418 & 0.0491 & 0.0577 & 0.0624 & 0.0812 \\
\hline 2.5 & 0.02018 & 0.0304 & 0.0427 & 0.0442 & 0.0605 & 0.0651 & 0.0771 & 0.0916 \\
\hline
\end{tabular}


The pressure strain is the main cause of pipe failure. In Table 2, the values of strain for diameter ratios to the thickness ranging from 45 to 112 have been presented. The more displacement, the more strain there is. By increasing the pipe thickness the strains in the pipe subjected to faulting displacement have also decreased, expressing the high importance of pipe thickness. Due to faulting displacement in addition to pressure strain, tensile strains are also created in the pipe. Regarding the results obtained from different values of displacement and diameter ratio to pipe thickness in Table 3, we sum up that pressure and the strain is the main reason of pipe failure.

In Figure 8, the strain graph of different diameter core for pipe thickness of the pipeline for fault displacement values from 0.2 to 3 meter is shown.

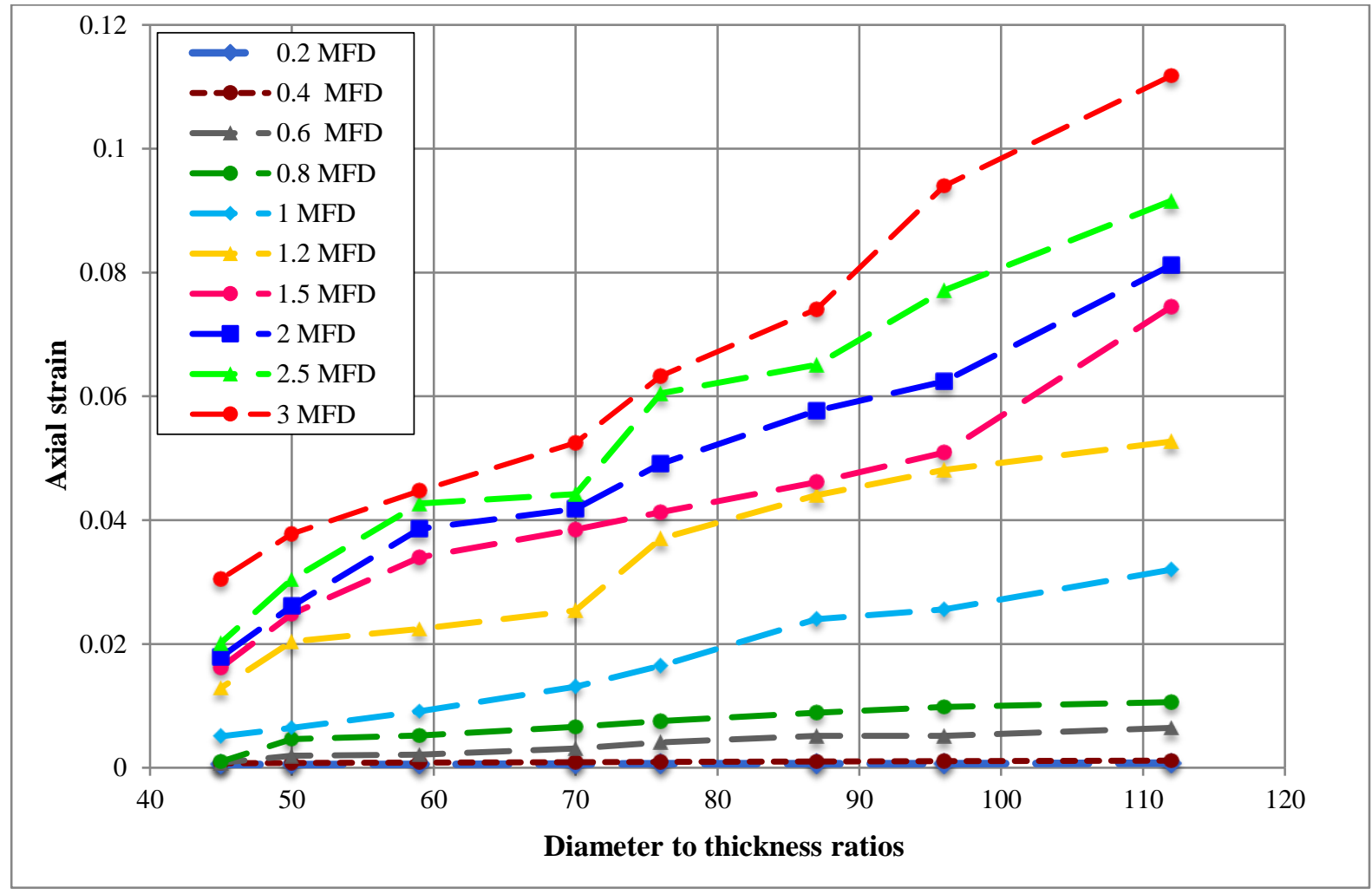

Figure 8. A graph of the strain tube diameter to thickness ratio (D/t) under the amount of 0.2 to 3 meters fault displacements (MFD)

\section{Conclusion}

In In this study on the response of buried steel pipes subjected to fault strike-slip, analyses of different values of the diameter ratio of 45 to 112 were conducted.

The summary results are as follows:

- 0.575 meter displacement at fault, the first strain caused by plastic pipes.

- The fault displacement of 0.6 meter, thickness to diameter ratio of 112 and 96 plastic strains formed. In diameter to thickness ratio of diameter to thickness of 86 the plastic strain is not formed.

- The fault displacement of 1 meter pipe failure mode is local buckling. Displacement and deformation of the tube are 1 meter looks like the letter $\mathrm{S}$.

- The fault displacement of 1.5 meter high (3 meter) failure mode tube is wrinkling. And changes in the tube shaped like the letter $\mathrm{Z}$ is the displacement of 1.5 meter.

- Large deformation and displacement of the local buckling of the steel pipe is greater than 1 meter.

- Reducing the thickness of the tube diameter of the tube wall has a positive effect on reducing local buckling and wrinkling.

- Reducing the diameter of the tube thickness reduces the strain of the fault pipes also compressive strain injury and failure of the pipe.

\section{References}

[1] O'Rourke, Michael J., and Xuejie Liu. Response of buried pipelines subject to earthquake effects. Multidisciplinary Center for 
Earthquake Engineering Research, University at Buffalo, 1999.

[2] Schiff, Anshel J. "Northridge earthquake: lifeline performance and post-earthquake response." ASCE, 1995.

[3] Chi, Wu-Cheng, Douglas Dreger, and Anastasia Kaverina. "Finite-source modeling of the 1999 Taiwan (Chi-Chi) earthquake derived from a dense strong-motion network." Bulletin of the Seismological Society of America 91, no. 5 (2001): 1144-1157.

[4] Horwich, George. "Economic lessons of the Kobe earthquake." Economic development and cultural change 48, no. 3 (2000): 521542.Douglas G. Honegger, M.EERI, Douglas J. Nyman, (2002) Trans-Alaska Pipeline System Performance in the 2002 Denali Fault, Alaska Earthquake. M.EERI, Elden R. Johnson, M.EERI, Lloyd S. C.

[5] Jibson, Randall W., Edwin L. Harp, William Schulz, and David K. Keefer. "Large rock avalanches triggered by the M 7.9 Denali Fault, Alaska, earthquake of 3 November 2002." Engineering geology 83, no. 1 (2006): 144-160.

[6] Newmark NM, Hall WJ. "Pipeline design to resist large fault displacement".. In: Proceedings of the US National Conference on Earthquake Engineering. Ann Arbor: University of Michigan (1975). p. 416-25.

[7] Kennedy, Robert P., A. M. Chow, and Robert A. Williamson. "Fault movement effects on buried oil pipeline." Transportation engineering journal of the American Society of Civil Engineers 103, no. 5 (1977): 617-633.

[8] Shinozuka, Masanobu, and Takeshi Koike. Estimation of structural strains in underground lifeline pipes. Columbia University, Department of Civil Engineering and Engineering Mechanics, 1979.

[9] Wang, Leon Ru - Liang, and Yaw - Hue Yeh. "A refined seismic analysis and design of buried pipeline for fault movement." Earthquake engineering \& structural dynamics 13, no. 1 (1985): 75-96.

[10] Chiou, Y-J., S-Y. Chi, and H-Y. Chang. "A study on buried pipeline response to fault movement." Journal of pressure vessel technology 116, no. 1 (1994): 36-41.

[11] TANABE, Kishiro, and Shiro TAKADA. "ESTIMATION OF EARTHQUAKE INDUCED SETTLEMENTS FOR LIFELINE ENGINEERINGS." Doboku Gakkai Ronbunshu 1988, no. 392 (1988): 377-384.

[12] Datta, T.K., 1999. Seismic response of buried pipelines: a state-of-the-art review. Nuclear Engineering and Design, 192(2), pp.271-284.

[13] ALA (2001) American Lifelines Alliance: seismic fragility formulations for water systems - guideline and appendices. American Lifelines Alliance, Washington DC, USA

[14] Takada, Shiro, Nemat Hassani, and Katsumi Fukuda. "A new proposal for simplified design of buried steel pipes crossing active faults." Earthquake engineering \& structural dynamics 30, no. 8 (2001): 1243-1257.

[15] Karamitros, Dimitrios K., George D. Bouckovalas, and George P. Kouretzis. "Stress analysis of buried steel pipelines at strikeslip fault crossings." Soil Dynamics and Earthquake Engineering 27, no. 3 (2007): 200-211.

[16] Abdoun, Tarek H., Da Ha, Michael J. O’Rourke, Michael D. Symans, Thomas D. O'Rourke, Michael C. Palmer, and Harry E. Stewart. "Factors influencing the behavior of buried pipelines subjected to earthquake faulting." Soil Dynamics and Earthquake Engineering 29, no. 3 (2009): 415-427.

[17] Vazouras, Polynikis, Spyros A. Karamanos, and Panos Dakoulas. "Finite element analysis of buried steel pipelines under strikeslip fault displacements." Soil Dynamics and Earthquake Engineering 30, no. 11 (2010): 1361-1376.

[18] Vazouras, Polynikis, Spyros A. Karamanos, and Panos Dakoulas. "Mechanical behavior of buried steel pipes crossing active strike-slip faults." Soil Dynamics and Earthquake Engineering 41 (2012): 164-180.

[19] Rofooei, Fayaz Rahimzadeh, Himan Hojat Jalali, Nader Khajeh Ahmad Attari, Hadi Kenarangi, and Masoud Samadian. "Parametric study of buried steel and high density polyethylene gas pipelines due to oblique-reverse faulting." Canadian Journal of Civil Engineering 42, no. 3 (2015): 178-189.

[20] Uckan, E., B. Akbas, J. Shen, W. Rou, F. Paolacci, and M. O’Rourke. "A simplified analysis model for determining the seismic response of buried steel pipes at strike-slip fault crossings." Soil Dynamics and Earthquake Engineering 75 (2015): 55-65.

[21]Khoshvatan, Mehdi, and Oghabi, Mohsen.” Evaluation of the seismic response of buried steel pipeline under strike-slip fault M.Sc thesis civil engineering Department, Islamic Azad University Kermanshah. (2016)

[22]Khoshvatan, Mehdi, and Oghabi ,."The numerical study of buckling and failure behavior of buried steel pipes under the permanent movement of the ground in the fault place".4th. International Congress on Civil Engineering, Architecture and Urban Development, Shahid Beheshti University, Tehran, Iran. December (2016)

[22] Uckan, E., Akbas, B., Cakir, F., Shen, J., O’Rourke, M., Caglar, M., \& Paolacci, F. PERFORMANCE EVALUATION OF BURIED STEEL PIPES SUBJECT TO STRIKE SLIP FAULT OFFSETS. 5th ECCOMAS Thematic Conference on Computational Methods in Structural Dynamics and Earthquake Engineering. Crete Island, Greece, 25-27 May (2015). 